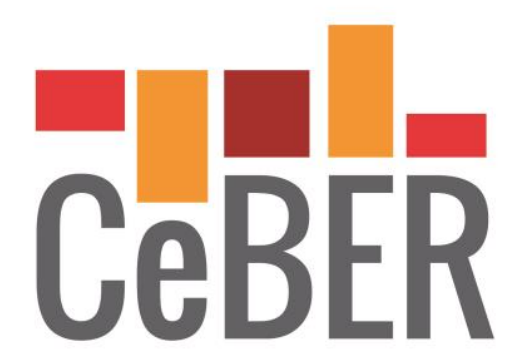

CENTRE FOR BUSINESS AND ECONOMICS RESEARCH

UNIVERSITY OF COIMBRA

\title{
The interconnections between Renewable Energy, Economic Development and Environmental Pollution. A simultaneous equation system approach
}

ELIAS SOUKIAZIS

CeBER and Faculty of Economics of the University of Coimbra SARA PROENÇA CERNAS/ESAC, Polytechnic Institute of Coimbra PEDRO ANDRÉ CERQUEIRA

CeBER and Faculty of Economics of the University of Coimbra

\section{CeBER Working Papers}

No. 10 


\title{
The interconnections between Renewable Energy, Economic Development and Environmental Pollution. A simultaneous equation system approach.
}

\author{
Elias Soukiazis $^{\mathrm{a}}$, Sara Proença ${ }^{\mathrm{b}}$ and P. A. Cerqueira ${ }^{\mathrm{a}}$
}

\begin{abstract}
The relationship between renewable energy sources and economic growth has attracted the interest of researchers in recent years. However, the analysis has focused mostly on measuring the impact of renewable energy consumption on economic performance (such as economic growth) that does not reflect the quality of standards of living. We employ a different approach measuring the impact of renewable energy consumption on the Human Development Index (HDI) that considers these qualitative characteristics associated with better health and educational standards along with income performance. Additionally, we develop a simultaneous equation system approach that describes the interrelations between economic variables, renewable energy and pollution emissions with feedback effect tendencies. We provide robust evidence using panel data for a set of 28 OECD countries over the period 2004-2015. The system of equations is estimated by 3 sls considering a static and dynamic specification of the model. It is shown that renewable energy consumption along with human and physical capital are important factors for explaining the sustainable development level of the countries considered. Renewable energy consumption is mostly determined by higher levels of human capital, the R\&D spending and the stage of countries' development. Factors like the stage of development, total energy consumption, renewable energy consumption and standard levels of education are important elements for explaining environmental pollution (measured by $\mathrm{CO} 2$ emissions per capita). It is also established a non-linear relationship between the countries`stage of development and carbon emissions.
\end{abstract}

Jel cod: O13, Q2, C33

Keywords: renewable energy, human development index, simultaneous equation system, panel data

Corresponding author: Elias Soukiazis, Faculty of Economics, University of Coimbra, Av. Dias da Silva, 165, 3004-512 Coimbra, Portugal, e-mail: elias@fe.uc.pt

a CeBER and Faculty of Economics of the University of Coimbra, Portugal

${ }^{\mathrm{b}}$ CERNAS/ESAC, Polytechnic Institute of Coimbra, Portugal 


\section{Introduction}

A large number of studies has considered the impact of new energy sources, other than fossilbased energy, on economic growth or the causality between the so-called renewable energies and economic growth. Although there is not a clear consensus, the majority of these studies provides evidence on the following aspects: renewable energies affect positively economic growth; the causality between renewable energy consumption and economic growth is mostly bidirectional; the new sources of energy favor the creation of new jobs in new sectors; and renewable energies are technology enhancing. Another important finding is that new energy sources alleviate the balance-of-payments dependence on fossil-based energy, especially in countries where this kind of energy sources is inexistent and has to be imported. Others point out the absence of macroeconomic instability resulted from the oil-price uncertainty and high price volatility that provoked in the past severe economic crises.

Almost all studies concentrated in the relation between renewable energy consumption and economic growth (or per capita income growth), and very few studied the impact of these sources of energy on improving the quality of the populations standards of living, which is measured by the Human Development Index $(H D I)$. The $H D I^{1}$ is a more accurate and broader measure of standards of living that takes into consideration also health conditions (through life expectancy) as well as education measurements (through years of schooling), along with income factors (gross national product per head). It has been established in the health economics literature that better health increases labor productivity and therefore economic growth (e.g. López-Casasnovas et al., 2005), and through the endogenous growth theory that human capital is the engine of growth (e.g. Romer, 1986; Lucas, 1988; Barro, 2001). Knowing that renewable energy contributes to better health conditions through lower environmental pollution and that it is linked to new technologies, the $H D I$ is more suitable than any other economic indicator commonly used in the literature to access the impact of renewable energies on the quality of the standards of living.

Another shortcoming in the literature is that most studies apply quantitative approaches to measure the relationship between income standards and renewable energy consumption without explaining the mechanism through which this connection operates. The models used are mostly non-theoretical in nature focusing on empirical evidence. Examples of these empirical frameworks are the causality tests trying to identify the direction of the relationship between income measures and renewable energy sources or cointegration techniques to ensure a nonspurious correlation, among other dynamic specification approaches. Few studies employ a simultaneous equation system approach that describes the important links and feedback effects between economic variables and renewable energy consumption ${ }^{2}$.

The aim of this paper is to contribute to the existing literature in two main aspects: first, using a more suitable indicator that measures the quality of standards of living, based on the HDI (which considers health and education conditions); second, employing a more suitable approach that

\footnotetext{
1 The United Nations Development Program created the Human Development Index that measures the quality of life in different countries on a scale from zero to one. This index apart from measurements, such as the gross national product, considers factors such as health and education when evaluating a country's progress.

${ }^{2}$ A recent survey on the relationships between energy, environment and economic growth by Tiba and Omri(2017) show that very few studies employ simultaneous equation models. Important exceptions are Omri (2013), Omri and Kahouli (2014) or Kahouli and Omri (2017).
} 
describes the important interconnections between economic indicators, renewable energy consumption and environmental pollution. The latter lies on a system of equations that can be estimated simultaneously, describing analytically the interconnections between variables characterized by reciprocal feedback effects with growth expanding tendencies.

The paper comprises the following sections. Besides the introduction, section 2 discusses briefly the literature review, outlining the main findings. The model description is made in section 3 . Section 4 explains the variables, the data, and stylized facts. Section 5 presents and discusses the obtained results from the static model and section 6 analyses the results from the dynamic model. The last section concludes.

\section{Literature Review}

The causal relationship between energy consumption and economic growth has been widely discussed in the energy economics literature over the past decades (for a review see, for example, Tiba and Omri, 2017; Menegaki, 2014; Ozturk, 2010; and Payne, 2010). This causal nexus has been explored in a large number of studies, using different approaches and country samples, and focusing mostly on four testable hypotheses:

i. The feedback hypothesis, supported by the bidirectional causality between energy consumption and economic growth, meaning that both variables influence each other reciprocally. Under this hypothesis, energy conservation policies, which reduce energy consumption, have a negative impact on economic growth performance, which in turn affects energy consumption negatively.

ii. The growth hypothesis, validated by the existence of a unidirectional causality running from energy consumption to economic growth. According to this view, energy consumption plays a vital role in enhancing higher economic growth. In this framework, energy conservation policies aimed at reducing energy consumption are expected to have negative impacts on economic growth.

iii. The conservation hypothesis, confirmed by the existence of a unidirectional causality running from economic growth to energy consumption. Therefore, higher GDP growth leads to increased energy consumption with no feedback effect. In this case, energy conservation policies or energy supply shocks will not affect economic growth adversely.

iv. The neutrality hypothesis, validated by the absence of causality between energy consumption and economic growth, i.e. the variables are independent. In this framework, policies targeting at reducing energy consumption have no impact on economic growth and vice versa.

Most of the empirical literature is focused on the causal relationship between energy consumption and economic growth. The renewable energy consumption/economic growth nexus is a relatively recent research topic in literature, which has gained increasing interest from both academics, and policy makers in the last ten years (Sebri, 2015). Empirical evidence on this relationship is mixed and no consensus has been achieved in the literature, as demonstrated below.

Among the existing studies, Apergis and Payne (2011) use an error correction model to examine the relationship between renewable energy consumption and economic growth for a panel of six Central American countries over the period 1980-2006. The empirical findings support the bidirectional causality hypothesis, in both the short-run and long-run analysis, i.e. the feedback 
hypothesis. The results from the heterogeneous panel cointegration test reveal a long-run equilibrium correlation between real GDP, renewable energy consumption, real gross fixed capital formation, and the labor force. The authors demonstrate this causal nexus between renewable energy consumption and economic growth in other research studies referred to other groups of countries, as well. For instance, using a multivariate framework, Apergis and Payne (2010a) support the feedback hypothesis for a panel of thirteen Eurasian countries over the period 1992-2007; Apergis and Payne (2010b) studied the same causality in the case of twenty OECD countries over the period 1985-2005, and Apergis and Payne (2012) considered a panel of eighty countries over the period 1990-2007. Similarly, Shahbaz et al. (2016) found a bidirectional relationship between biomass energy consumption and economic growth for the group of the BRICS countries over the period 1991Q1-2015Q4. Pao and Fu (2013) also support the feedback effect among renewable energy consumption and economic growth in a study for Brazil using time series data from 1980 to 2010.

For a panel of twenty OECD countries, Ohler and Fetters (2014) implement an error correction model to analyze the causal relationship between economic growth and renewable electricity generation disaggregated by renewable energy sources (biomass, geothermal, hydro, solar, waste, and wind) considering data from 1990 to 2008. The results indicate bidirectional causality between aggregate renewable electricity generation and real GDP growth, supporting the feedback hypothesis. For the individual sources of renewable electricity, the results are as follows: i) hydro and waste energy show a short-run positive bidirectional relationship with real GDP growth; ii) hydro, waste, biomass, and wind energy exhibit a positive long-run relationship with real GDP growth; and iii) biomass, hydro, and waste electricity generation have the largest impact on real GDP growth in the long-run.

Koçak and Şarkgüneşi (2017) use a panel data analysis to examine the long-run relationship between renewable energy consumption and economic growth in a sample that involves, among others, some Black Sea and Balkan countries (Albania, Bulgaria, Georgia, Greece, Macedonia, Romania, Russian F., Turkey and Ukraine) for the period 1990-2012. This study employs the neoclassical production function framework, relating the per capita GDP growth, with gross fixed capital formation, labor force participation, and the share of renewable energy in total energy consumption. The estimation results show a positive long-term equilibrium relationship between renewable energy consumption and economic growth. In particular, their evidence supports the feedback hypothesis for the panel data set including all nine countries; the growth hypothesis in Bulgaria, Greece, Macedonia, Russia and Ukraine; the neutrality hypothesis in Turkey; and the feedback hypothesis in Albania, Georgia and Romania.

In a recent study, Inglesi-Lotz (2016) investigates the impact of renewable energy consumption on economic welfare for 34 OECD countries from 1990 to 2010, using a multivariate framework based on the production function. The cointegration approach indicates that there is a long-run equilibrium relationship between real GDP (or real GDP per capita), renewable energy consumption (or its share to the total energy mix), real gross fixed capital formation, employment, and the R\&D expenditures. Results show that a $1 \%$ increase of renewable energy consumption will increase GDP by $0.105 \%$ and GDP per capita by $0.100 \%$, while a $1 \%$ increase of the renewable energy share will induce a $0.089 \%$ increase in GDP, and $0.090 \%$ increase in GDP per capita. These empirical findings support the growth hypothesis that higher renewable consumption induces higher income growth. Another study by Bilgili (2015) uses wavelet coherence analyses to examine the relationship between renewable energy consumption and 
industrial production in the United States from 1981 to 2013, and the results also support the growth hypothesis. Similarly, Bilgili and Ozturk (2015), using dynamic panel data over the period 1980-2009, concluded that there is a unidirectional causality from biomass energy consumption to economic growth in the G7 countries. The growth hypothesis is also supported by findings from Ozturk and Bilgili (2015) for a panel of 51 sub-Saharan African countries in the period 19802009, using a dynamic panel analysis, Hamit-Haggar (2016) using panel data for 11 sub-Saharan African countries over the period 1971-2007, and Tiwari (2011) for India over the 1960-2009 period using a structural vector autoregressive approach.

On the same subject, Fang (2011) evaluates the role of both, the amount and share of renewable energy consumption in economic welfare for China from 1978 to 2008, using a production function and a multivariate ordinary least squares (OLS) approach. The author found that: i) an increase in renewable energy consumption increases real GDP; ii) the impact of renewable energy consumption share on economic welfare is insignificant; and iii) an increasing share of renewable energy consumption negatively affects economic welfare growth.

Sadorsky (2009a) employs the cointegration techniques to investigate the relationship between renewable energy consumption and income for a panel of 18 emerging economies over the period 1994-2003. His evince shows that increases in real GDP per capita have a positive and statistically significant impact on renewable energy consumption per capita with no feedback effect, supporting the view of a unidirectional causality running from economic growth to renewable energy consumption in the long term, i.e. the conservation hypothesis. In the same line, Sadorsky (2009b), using a panel data model to estimate the renewable energy consumption for the G7 countries over the period 1980-2005, finds that real GDP per capita and $\mathrm{CO}_{2}$ emissions per capita are the major drivers of per capita renewable energy consumption in the long-run. Indeed, a $1 \%$ increase in real GDP leads to an increase of $8.44 \%$ in renewable energy consumption while a $1 \%$ increase in $\mathrm{CO}_{2}$ emissions leads to a $5.23 \%$ increase in renewable energy. Oil price increases have small and negative impact on renewable energy consumption. Ocal and Aslan (2013) also support the conservation hypothesis. The authors examine the renewable energy consumption/economic growth causality nexus in Turkey from 1990 to 2010 using an ARDL approach and the Toda-Yamamoto causality tests. Empirical results indicate that renewable energy consumption has a negative impact on economic growth and that there is a unidirectional causality running from economic growth to renewable energy consumption.

Menegaki (2011) also investigates the causal relationship between economic growth and renewable energy consumption for twenty-seven European countries in a multivariate panel framework from 1997 to 2007 using a random effect model. The empirical tests reveal that there is no causality between renewable energy consumption and GDP in either the short- or long-run, suggesting evidence in favor of the neutrality hypothesis in Europe. Payne (2009) uses the TodaYamamoto causality tests to examine the nexus between renewable and non-renewable energy consumption and economic growth for the United States over the period 1949-2006, and the results also support the neutrality hypothesis. Dogan (2015), in a study for Turkey using the Granger causality test, supports the neutrality hypothesis between economic growth and electricity consumption from renewable sources in the short-run, while in the long run the results support the growth hypothesis.

In the same line of research, Bhattacharya et al. (2016) investigate the effects of renewable energy consumption on economic growth for 38 top renewable energy-consuming countries in the world 
using heterogeneous panel estimation techniques over the period 1991-2012. Empirical findings support evidence of the long-run dynamics between economic growth, traditional inputs such as capital and labor, and both renewable and non-renewable energy inputs. The long-run output elasticities suggest that renewable energy consumption has a significant positive impact on economic growth for $57 \%$ of the sample countries. In the short-run, results support the neutrality hypothesis of no causality between real GDP and renewable energy consumption.

A different approach is used by Ewing et al. (2007) based on the generalized variance decomposition technique to explore the relationship between disaggregated energy consumption (coal, oil, natural gas, hydropower, wind, solar, wood and waste) and industrial output in the United States over the period of 2001:1-2005:6. They find evidence that, for industrial production, supply shocks of non-renewable energy sources have the highest impact on the output variation. Total renewable energy consumption explains $2.3 \%$ of forecast error variance - waste $10.6 \%$, wood $6 \%$, wind $5.8 \%$, solar $3.8 \%$ and hydropower $1.9 \%$, which represents a small impact on economic growth in the case of the United States. The link between disaggregate energy consumption and industrial output is also examined by Sari et al. (2008), using the autoregressive distributed lag (ARDL) approach for the United Sates over the 2001:1-2005:6 period. Results suggest that industrial production has a negative impact on solar energy consumption and a positive impact on hydropower, waste, and wind energy consumption.

Alper and Ogus (2016) explore the causal relationship among economic growth, renewable energy consumption, capital and labor force for a group of eight EU member countries (Bulgaria, Cyprus, Czech Republic, Estonia, Hungary, Poland, Romania, and Slovenia) covering the period 1990-2009 period. The authors use the asymmetric causality test approach and the autoregressive distributed lag (ARDL) model. Their results indicate that renewable energy consumption has positive impacts on economic growth for all sample countries. However, this effect is statically significant only for Bulgaria, Estonia, Poland and Slovenia. The findings support the neutrality hypothesis for Cyprus, Estonia, Hungary, Poland and Slovenia; the conservation hypothesis for Czech Republic; and the growth hypothesis for Bulgaria. Mixed results are also found by Tugcu et al. (2012) using data for G7 countries over the period 1980-2009. The authors explore the causal relationships between renewable and non-renewable energy consumption and economic growth using the classical and augmented production functions and performing the Hatemi-J causality tests. Results indicate that although the bidirectional causality is found for all countries in the case of the classical production function, mixed results are supported for each country when the production function is augmented. In particular, there is no causal relationship between renewable energy consumption and economic growth in the case of France, Italy, Canada and the USA; bidirectional causality is found for England and Japan, and the conservation hypothesis is supported for Germany.

Finally, but not least, Al-mulali et al. (2013) found mixed results for a sample of more than 108 countries categorized as low income, lower middle income, upper middle income, and high income over the period 1980-2009, using the fully modified least squares (FMOLS) method. The empirical results indicate that $79 \%$ of the countries show a positive bi-directional long run relationship between renewable energy consumption and GDP growth, supporting the feedback hypothesis. The neutrality hypothesis is supported in $19 \%$ of the countries, and the remaining $2 \%$ of the countries, show a unidirectional causality, supporting the conservation hypothesis or the growth hypothesis. 
The empirical literature is extensive but most studies have focused on the relationship between conventional economic indicators and energy consumption and few consider the welfare gains from the renewable energy consumption or the improvements on the quality of the standards of livings. On the other hand, most of the approaches used are quantitative in nature and not attempt has been made to explain the mechanism behind the important connection between economic variables and renewable energy consumption. In this paper, we employ a different approach by tackling these shortcomings in the literature: (i) we use a different economic indicator based on the Human Development Index linked to the sustainable economic growth and development concept; (ii) we implement a system of simultaneous equations which describes the important feedback linkages between economic development, renewable energy sources, human capital and environmental pollution; (iii) the important linkages between these variables is driven by the reciprocal correlation between the core variables of the system which generates expanding and sustainable tendencies.

\section{The model}

The structural model employed consists of three main behavioral equations, which explain the important linkages between economic development, renewable energy sources, and environmental pollution. The first equation determines the factors that explain the level of country's sustainable development, given as follows:

$$
H D I_{i t}=\alpha_{i}+\alpha_{1} K p c_{i t}+\alpha_{2} \operatorname{Pop}_{i t}+\alpha_{3} H K_{i t}+\alpha_{4} L E_{i t}+\alpha_{5} R N E_{i t}+\alpha_{6} C O 2_{i t}+\varepsilon_{1, i t}
$$

The Human Development Index $(H D I)$ is used as a proxy for the sustainable development level of each country. As in the conventional growth approach, the basic input factors capital $(K p c)$ and population (Pop) are included to explain the country's development stage, with the expected positive $\left(\alpha_{1}>0\right)$ and negative $\left(\alpha_{2}<0\right)$ impacts, respectively. The latter effect is explained by the decrease in per capita income as population increases, affecting negatively the HDI since less income will be distributed among a larger population. Additionally, and in line with the endogenous growth theory, human capital $(H K)$ and health standards, through live expectancy, $(L E)$ are important determinants, influencing positively the stage of development of any economy, expecting therefore $\alpha_{3}>0$ and $\alpha_{4}>0$. Furthermore, it is of particular interest to measure the impact of renewable energy consumption $(R N E)$ on the sustainable development index, expecting a positive and statistically significant effect $\left(\alpha_{5}>0\right)$, while the pollution factors through $\mathrm{CO} 2$ emissions are expected to influence negatively the development level $\left(\alpha_{6}<0\right)$, explained by the negative impact of pollution emissions on living standards. The constant term $\left(\alpha_{i}\right)$ captures country specific effects, which are invariant in time such as the country size, natural resources, location, institutions and religion, among others.

The second equation of the system explains the determinants of the renewable energy consumption variable, as follows: 
In equation (2) we state that the renewable energy consumption depends on the development level $(H D I)$, assessing the feedback effect, and in conjunction with equation (1) the bidirectional causality assumption. More advanced countries will invest more in the promotion of renewable energy, therefore it is expected that $\beta_{1}>0$. In addition, we assume that $R \& D$ expenses as share of income are important for developing renewable energy technologies, expecting also $\beta_{2}>0$. Higher spending on research and development activities is a necessary condition for developing environmentally clean energy projects based on advanced technology. In addition to the spending aspect on research, higher levels of human capital and knowledge accumulation are necessary requirements for discovering new energy sources more environmentally friendly, expecting therefore $\beta_{3}>0$. It should also be noticed that the use of nuclear energy (NUCE) as an alternative energy source would condition the development of renewable energy use, affecting therefore negatively the production and consumption of this type of energy, expecting hence $\beta_{4}$ to appear with a negative sign. Furthermore, $P F E$ is the price of fossil energy that can encourage the usage of renewable energy through the substitution effect, expecting $\beta_{5}$ to be positive. Finally, EnDep is the energy dependence from abroad defined as the share of imported energy in total energy consumption. It is expected that high external energy dependence (mainly fossils-based energy) will encourage countries to develop new clean energy sources $\left(\beta_{6}>0\right)$ with the aim of reducing the pressure on the balance of payments, and at the same time reducing the atmospheric pollution. The constant term $\left(\beta_{i}\right)$ reflects specific differences among countries that are invariant in time.

The third equation of the system reflects the need of modern societies (especially in advanced levels of development) to enhance economic activity with the usage of clean sources of energy. Therefore, the incidence of $\mathrm{CO} 2$ emissions can be modeled as follows:

$$
C O 2_{i t}=\gamma_{i}+\gamma_{1} H D I_{i t}+\gamma_{2} H D I_{i t}^{2}+\gamma_{3} T E N C_{i t}+\gamma_{4} R N E_{i t}+\gamma_{5} H K_{i t}+\varepsilon_{i t}
$$

In equation (3) we relate $\mathrm{CO} 2$ emissions with development level and its squared value in order to test the environmental Kuznets curve (EKC) hypothesis of an inverted U-shaped relationship between environmental degradation and economic development (Kuznets, 1955). The EKC hypothesis postulates that environmental degradation increases during the early stages of economic growth, but beyond some level of development the trend reverses, so that for high income levels economic growth leads to environmental improvement. There is therefore a threshold point in the development level that beyond this, countries implement measures to reduce atmospheric pollution. In order to confirm the EKC hypothesis, we expect $\gamma_{1}>0$ and $\gamma_{2}<0$ and both being statistically significant. It is rational to assume that the increase of total energy consumption (TENC) will contribute to higher $\mathrm{CO} 2$ emissions, since a great part of the consumed energy is fossil extracted, expecting therefore $\gamma_{3}>0$. On the other hand, the use of renewable energies $(R N E)$, which are environmentally friendly, contribute to reduce atmospheric pollution $\left(\gamma_{4}<0\right)$. Finally, educational standards will help to reduce atmospheric pollution for two reasons: educated population becomes more sensitive to air pollution, and higher human capital skills will contribute to develop clean energy technology, therefore it is expected that $\gamma_{5}<0$. It is assumed that each country has its own intercept $\left(\gamma_{i}\right)$ representing country specific effects that remain constant in time. 
The above three equations constitute a system that describes the important linkages between economic variables, energy strategies and pollution reduction goals. Through equation (3), a moment will come that countries will realize that should develop alternative energy strategies aiming to reduce the environmental pollution and this will depend on its level of development. Through equation (2), the $R \& D$ projects and qualified human capital, as well as the development level, will contribute to develop new clean energy technologies, namely renewable energy more friendly to the environment. Through equation (1), renewable energy along with other factor inputs will contribute to promote sustainable economic development. The core variables of the model interrelated to each other are, human development index $(H D I)$, renewable energy $(R N E)$ and $\mathrm{CO} 2$ emissions, which are treated as endogenous in the system. At the heart of this circular interconnection process is the understanding of the policy makers that renewable energy promotes higher economic development without deteriorating the environment, and take measures to this direction. This will imply the reallocation of resources to the $R \& D$ activities and to human capital skills to develop new energy policies more friendly to the environment.

The above three equations will be estimated by $3 s l s$, the most efficient estimation approach that controls for the endogeneity of regressors and takes into consideration the cross-equation error correlation.

\section{Variable's description and stylized facts}

The variables used to estimate the three equations of the system are described in Table 1 and their meaning is self-explained. As stated in the introduction, we consider a more suitable economic variable, the Human Development Index (HDI), which includes human capital skills and health standards. We have to notice that we use two variables to express human capital skills: the average years of schooling $(H K l)$ and the percentage of college degree to capture higher levels of education $(H K 2)$. On the other hand, life expectancy $(L E)$ is the variable used to express the health status of the population, as usually employed in the literature. To include the price effect of fossil energy in our model, we use three price proxies, namely the oil, gas and coal price (since there is not any aggregate price measure representing the entire non-renewable energy sector). Moreover, the oil price displays higher statistical relevance in the estimation approach. Table 1 also reports the unit measurement of each variable as well as the respective data source. 
Table 1. Variables definition and data source

\begin{tabular}{|c|c|c|c|}
\hline $\begin{array}{c}\text { Variable } \\
\text { designation }\end{array}$ & Definition & Unit & Data Source \\
\hline$H D I$ & Human development index & Index from 0 to 100 & \multirow{2}{*}{$\begin{array}{l}\text { United Nations Development } \\
\text { Programme - Human } \\
\text { Development Reports (April } \\
\text { 2017) }\end{array}$} \\
\hline$H K 1$ & Mean years of schooling & Years & \\
\hline$K p c$ & $\begin{array}{l}\text { Gross fixed capital } \\
\text { formation per capita }\end{array}$ & $\begin{array}{l}\text { Million US dollars at } \\
\text { current prices and PPPs }\end{array}$ & \multirow{2}{*}{$\begin{array}{l}\text { AMECO database (April } \\
\text { 2017) }\end{array}$} \\
\hline Pop & Total population & 1000 persons & \\
\hline$L E$ & Life expectancy at birth & Years & \multirow{7}{*}{$\begin{array}{l}\text { Eurostat database (April } \\
\text { 2017) }\end{array}$} \\
\hline$H K 2$ & $\begin{array}{l}\text { Population aged } 15-64 \\
\text { with tertiary educational } \\
\text { attainment (ISCED 5-8) }\end{array}$ & Percentage & \\
\hline$R \& D$ & $\begin{array}{l}\text { Total research and } \\
\text { development expenditure }\end{array}$ & Percentage of GDP & \\
\hline RNEshare & $\begin{array}{l}\text { Renewable energy } \\
\text { consumption }\end{array}$ & $\begin{array}{lrr}\text { Share of renewable } \\
\text { energy } & \text { (percentage) in } \\
\text { final } & \text { energy } \\
\text { consumption } & \end{array}$ & \\
\hline NUCE & $\begin{array}{l}\text { Nuclear energy } \\
\text { consumption }\end{array}$ & $\begin{array}{l}\text { Share of nuclear energy } \\
\text { (percentage) in final } \\
\text { energy consumption }\end{array}$ & \\
\hline EnDep & Energy dependence & $\begin{array}{l}\text { Percentage (net imports } \\
\text { divided by the sum of } \\
\text { gross inland energy } \\
\text { consumption rus } \\
\text { maritime bunkers) }\end{array}$ & \\
\hline TENC & $\begin{array}{l}\text { Final energy consumption } \\
\text { per capita }\end{array}$ & $\begin{array}{l}\text { Thousand tonnes of oil } \\
\text { equivalent (TOE) }\end{array}$ & \\
\hline$C O 2 p c$ & $\begin{array}{l}\text { Greenhouse gas (GHG) } \\
\text { emissions per capita }\end{array}$ & $\begin{array}{l}\text { Tonnes of } \mathrm{CO} 2 \\
\text { equivalent per capita }\end{array}$ & Eurostat database (July 2017) \\
\hline PFEoil & Crude oil price & $\begin{array}{l}\text { US dollars per million } \\
\text { Btu - OECD countries } \\
\text { cif }\end{array}$ & \multirow{3}{*}{$\begin{array}{l}\text { BP Statistical Review of } \\
\text { World Energy June } 2016 \\
\text { (April 2017) }\end{array}$} \\
\hline PFEgas & Natural gas price & $\begin{array}{l}\text { US dollars per million } \\
\text { Btu - Average German } \\
\text { Import Price }\end{array}$ & \\
\hline PFEcoal & Coal price & $\begin{array}{l}\text { US dollars per tonne - } \\
\text { Northwest } \\
\text { marker price }\end{array}$ & \\
\hline
\end{tabular}


Table 2 provides a summary of basic data descriptive statistics. It reveals that we use a balanced panel data model of 336 total observations for a set of 28 OECD countries ${ }^{3}$, covering the period 2004 to 2015 where data are available for all variables.

Table 2. Descriptive statistics

\begin{tabular}{|l|r|r|r|r|r|}
\hline \multicolumn{1}{|c|}{ Variable } & Observations & \multicolumn{1}{c|}{ Average } & \multicolumn{1}{c|}{$\begin{array}{c}\text { Standard } \\
\text { deviation }\end{array}$} & \multicolumn{1}{c|}{ Min. } & \multicolumn{1}{c|}{ Max. } \\
\hline HDI & 336 & 85.63095 & 4.10978 & 75 & 13.3 \\
\hline HKI & 336 & 11.19792 & 1.22266 & 1.93 & 19.18 \\
\hline Kpc & 336 & 6.96935 & 2.85419 & 401.16 & 81687 \\
\hline Pop & 336 & 17929.1 & 22678.8 & 70.6 & 83.3 \\
\hline LE & 336 & 78.55685 & 3.14831 & 8.7 & 39.6 \\
\hline HK2 & 336 & 22.7875 & 7.32049 & 0.34 & 3.75 \\
\hline R\&D & 336 & 1.48506 & 0.87905 & 0.1 & 53.9 \\
\hline RNEshare & 336 & 15.46845 & 11.22549 & 0 & 89.58 \\
\hline NUCE & 336 & 15.38181 & 20.18158 & -49.8 & 104.1 \\
\hline EnDep & 336 & 55.9122 & 27.67588 & 0.94 & 9.61 \\
\hline TENC & 336 & 2.49207 & 1.40273 & 4.98 & 31.18 \\
\hline CO2pc & 336 & 10.59354 & 4.30936 & 6.27 & 18.82 \\
\hline PFEoil & 336 & 13.28833 & 4.23684 & 4.3 & 11.6 \\
\hline PFEgas & 336 & 8.50083 & 2.12439 & 56.64 & 147.67 \\
\hline PFEcoal & 336 & 85.34 & 25.3718 & & \\
\hline
\end{tabular}

Some interesting figures on the core variables of our model show that the HDI varies between 75 and 93 (the initial index from 0 to 1 has been multiplied by 100), with Bulgaria (79.4) and Romania (80.2) standing at the lowest development levels, while the Netherlands (92.4), Denmark (92.5) and Germany (92.6) occupying the highest levels, based on the 2015 values. Figure 1 provides a more complete comparison among the countries considered in our sample, reporting values for the first (2004) and last (2015) years of the period considered. In all cases, there is an improvement in the development index level over time.

\footnotetext{
${ }^{3}$ Country sample: Austria (AT), Belgium (BE), Bulgaria (BG), Croatia (HR), Czech Republic (CZ), Cyprus (CY), Denmark (DK), Estonia (EE), Finland (FI), France (FR), Germany (DE), Greece (EL), Hungary (HU), Ireland (IE), Italy (IT), Latvia (LV), Lithuania (LT), Luxembourg (LU), Malta (MT), Netherlands (NL), Poland (PL), Portugal (PT), Romania (RO), Slovenia (SI), Slovakia (SK), Spain (ES), Sweden (SE), and United Kingdom (UK).
} 
Figure 1. Human Development Index (HDI) for 28 OECD countries

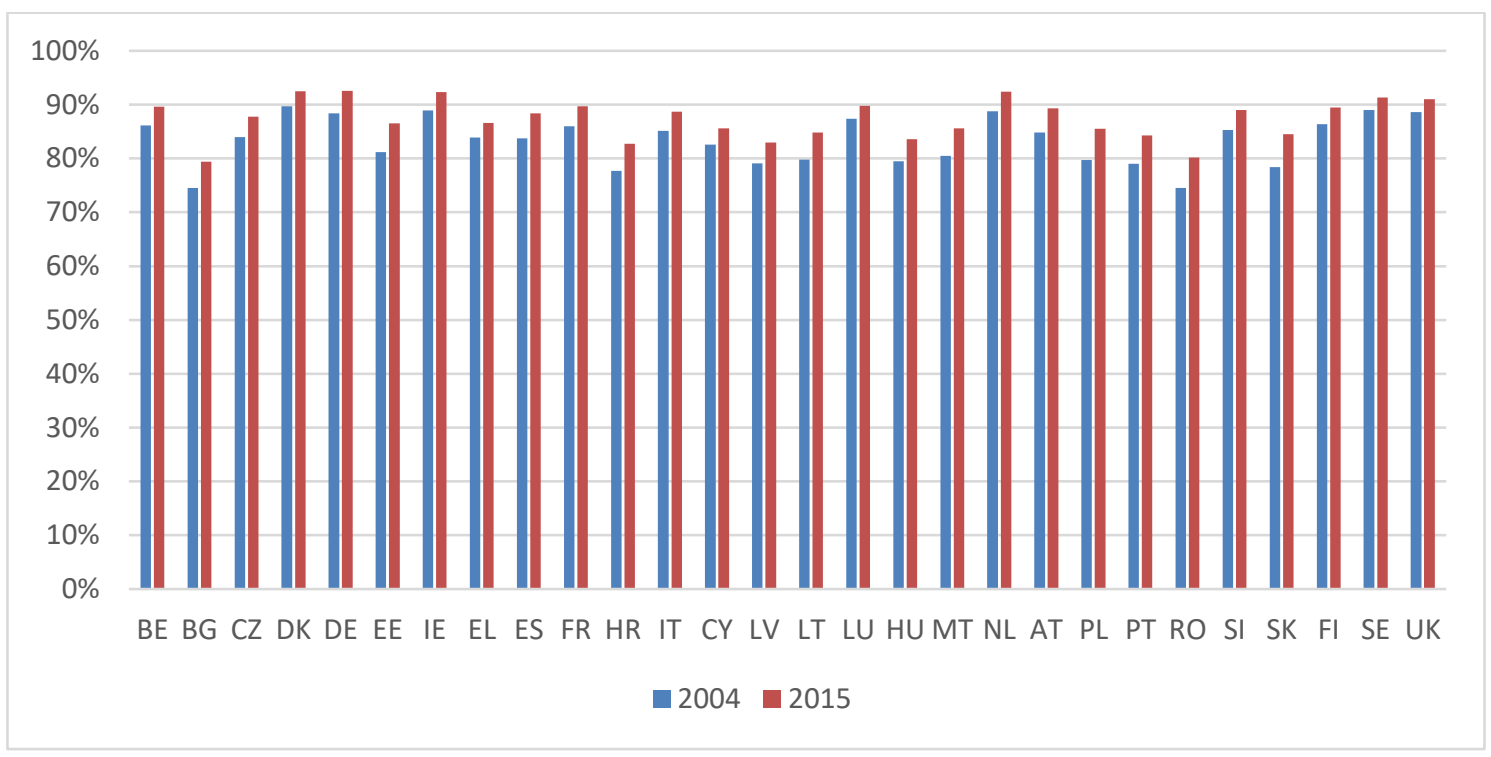

Concerning the share of renewable energy in final energy consumption (Figure 2), the values vary between 5\% and 53.9\%, revealing a high heterogeneity among countries. Luxembourg $(5.0 \%)$, Malta (5.0\%) and the Netherlands (5.8\%) are the countries with the lower use of renewable energy, while Sweden (53.9\%), Finland (39.3\%) and Latvia (37.6\%) are the pioneers in the use of cleaner energy sources, considering values of the year 2015. It should be noticed that all countries improved their position in the consumption of renewable energy over time.

Figure 2. Share of renewable energy in final energy consumption

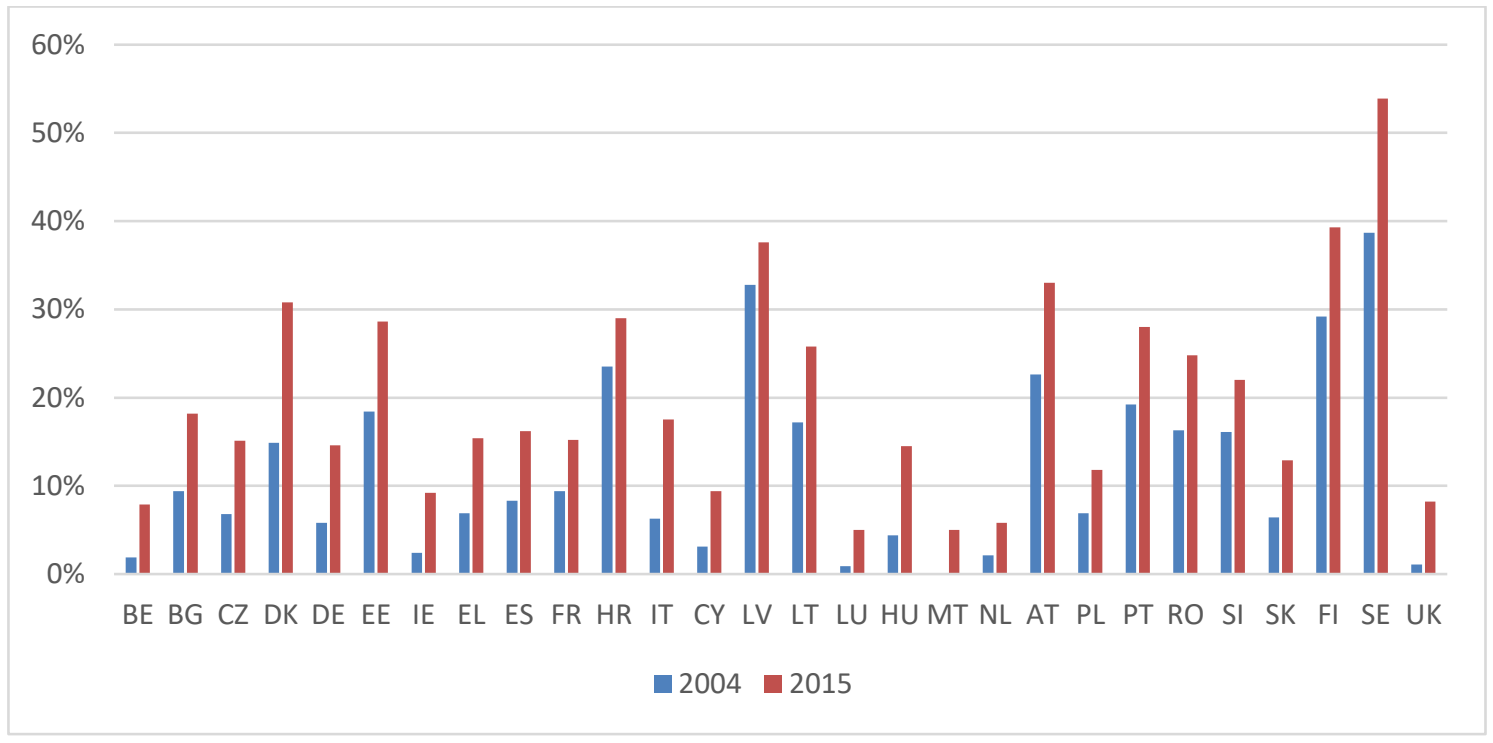


With respect to $\mathrm{CO} 2$ emissions per capita the values fluctuate between 4.98 and 31.18 tonnes (see Table 2 and Figure 3), with countries like Luxembourg (20.75), Estonia (13.78) and Ireland (13.49) exceeding the average value (10.59), while countries as Croatia (5.65), Sweden (5.73), Latvia (5.87), Romania (5.93) and Malta (6.01) revealing the lowest levels of atmospheric pollution in 2015. Figure 3 illustrates analytically for all countries the evolution of $C O 2$ emissions over time. We can see that all countries made an effort to reduce atmospheric pollution except Bulgaria, Latvia and Lithuania.

Figure 3. $\mathrm{CO} 2$ emissions per capita

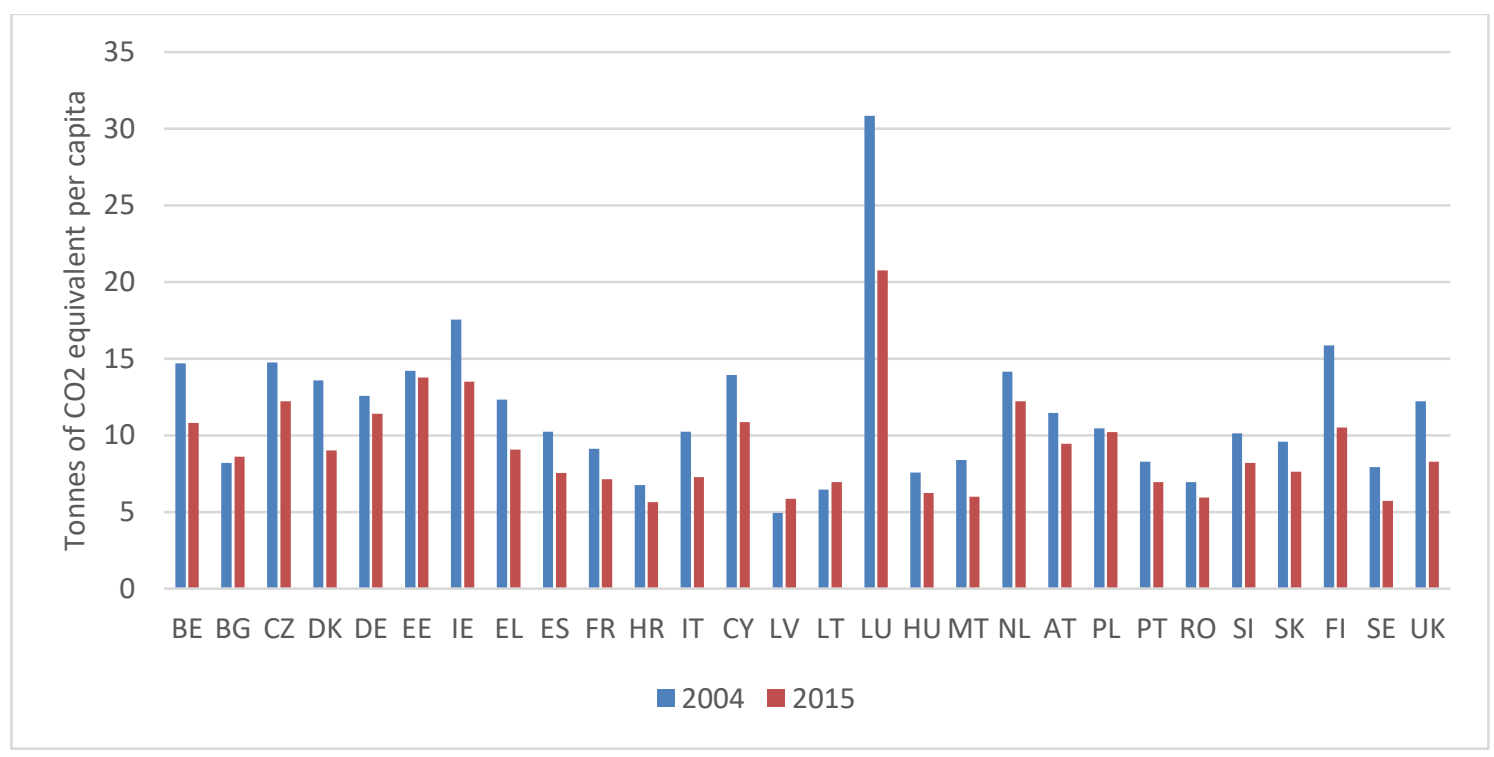

Other figures worth mentioning are related to the education skills measured by the average years of schooling, where the U.K. (13.3) comes first followed by Germany (13.2), Denmark (12.7) and Lithuania (12.7), in 2015. The lower levels of education concern countries like Portugal (8.9), Spain (9.8), Greece (10.5), Bulgaria (10.8) and Romania (10.8). On the other hand, higher levels of tertiary education (population aged 15-64 with tertiary educational attainment) register countries like U.K. (37.6\%) followed by Ireland (37.4\%), Cyprus (36.4\%) and Finland (35.5\%), while lower levels report countries as Romania (15.0\%), Italy (15.5\%), Malta (18.1\%), and Croatia (19.6\%). If we look at the R\&D spending share (as percentage of GDP), Sweden (3.26\%) is in the top, followed by Austria (3.07\%), Denmark (3.03\%), and Finland (2.90\%), while lower R\&D spending countries are Cyprus $(0.46 \%)$, Romania $(0.49 \%)$, Latvia $(0.63 \%)$ and Malta $(0.77 \%)$. With respect to health status, the life expectancy figures are used to express good health performance among countries. Checking the data, countries like Spain (83.0), Italy (82.7), Luxembourg (82.4) and France (82.4) have high average life expectancy, in contrast to countries like Lithuania (74.6), Bulgaria (74.7), Latvia (74.8) and Romania (75.0). In our sample, the average value of life expectancy is 78.6 years.

From the analysis of the data we can infer that despite the set of 28 OECD countries included in our sample are developed countries, the differences among them are significant. 


\section{Empirical evidence and discussion}

In the estimation approach, we use a sample of 28 OECD countries with data covering the most recent period 2004-2015 where statistical information is available. The three equations of the system are estimated by $3 s l s$ using the fixed effects panel estimation approach. This approach takes into consideration the following aspects: (i) it assumes different intercepts for each country capturing differences among them which are invariant in time; (ii) it takes into account the endogeneity problem of regressors (using all the remaining exogenous variables of the system as instruments); and (iii) it considers the interconnection between the three equations through the cross-equation error correlations. To control the effects of the financial crisis we use a timedummy variable that takes the value of one in the year 2008 and zero elsewhere. The obtained full-information regression results are reported in Table 3.

\subsection{The determinants of sustainable development}

The first column of Table 3 corresponds to equation (1), where the dependent variable is the HDI (index from 0 to 100); $K p c$ denotes the gross fixed capital formation per capita as proxy for capital accumulation $^{4}$ (millions of US dollars in PPP terms); Pop is total population (in thousands); HK1 is the average years of schooling, reflecting the average stock of knowledge; $L E$ is life expectancy at birth that aims to express the health status of each country; RNEshare is the share of renewable energy in final energy consumption; and $\mathrm{CO} 2 p c$ is carbon dioxide emissions per capita. The $3 s l s$ approach estimates simultaneously the three equations of the system by using the GLS estimator. All variables are expressed in logarithms except those that are in ratio (percentage) and the variable years of schooling.

As seen from Table 3 (Eq.1), the majority of coefficients are statistically significant and the goodness of fit (overall $\mathrm{R}^{2}$ ) indicates a high degree of explanation of the covariates. In addition, the joint significance of coefficients ( $\mathrm{Chi}^{2}$-stat) is also confirmed at the highest significance level of $1 \%$. Furthermore, all coefficients carry their expected signs, but not all of them display statistical significance. In particular, the proxy for capital accumulation has a positive effect on the level of sustainable development and it is statistically significant at the highest $1 \%$ level. This result reveals that, on average, a one percent increase in capital stock (per capita) is responsible for 0.0075 point increase (of the scale from 1 to 100) in the HDI, ceteris paribus. Population has a negative effect on the development index since less income will be distributed among a higher number of inhabitants and its statistical significance is confirmed almost at the $10 \%$ level.

Human capital in the form of the average years of schooling attainment has also a positive effect on the development index, revealing that each additional year of this level of education augments the human development index by approximately 0.60 points (of the scale from 1 to 100 ), and it is statistically significant at the $1 \%$ level. Although health status through the prolongation of life expectancy has its expected positive impact on the development level, it is not statistically significant at the conventional levels. Since our sample encompasses developed economies with no substantial differences in this health indicator (see Table 2), this is not a surprising result.

\footnotetext{
${ }^{4}$ We use capital formation per capita to be consistent with other variables in the system that are expressed in the same unit.
} 
Table 3. Estimation results of the system: Economic Development-Renewable Energy-CO2 Emissions, 3sls fixed effects panel data, 28 OECD countries, 2004-2015

\begin{tabular}{|c|c|c|c|}
\hline Variable & $\begin{array}{c}\text { Eq. (1) } \\
\text { Dependent variable } \\
H D I\end{array}$ & $\begin{array}{c}\text { Eq. (2) } \\
\text { Dependent variable } \\
\text { RNEshare }\end{array}$ & 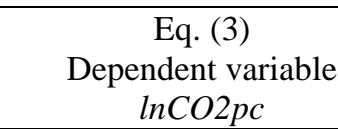 \\
\hline constant & $\begin{array}{l}74.59379(2.43) \\
{[0.015]^{* *}}\end{array}$ & $\begin{array}{l}-141.7584(-13.86) \\
{[0.000]^{* * *}}\end{array}$ & $\begin{array}{l}-19.55718(-5.90) \\
{[0.000]^{* * *}}\end{array}$ \\
\hline $\ln K p c$ & $\begin{array}{l}0.7524309(3.34) \\
{[0.001]^{* * *}}\end{array}$ & & \\
\hline $\ln P o p$ & $\begin{array}{l}-4.129443(-1.62) \\
{[0.106]^{*}}\end{array}$ & & \\
\hline$H K 1$ & $\begin{array}{l}0.6046017(6.07) \\
{[0.000]^{* * *}}\end{array}$ & & $\begin{array}{l}-0.0825872(-6.08) \\
{[0.000]^{* * *}}\end{array}$ \\
\hline$H K 2$ & & $\begin{array}{l}0.1279895(3.57) \\
{[0.000]^{* * *}}\end{array}$ & \\
\hline $\ln L E$ & $\begin{array}{l}12.18933(1.12) \\
{[0.264]}\end{array}$ & & \\
\hline RNEshare & $\begin{array}{l}0.3073812(3.03) \\
{[0.002]^{* * *}}\end{array}$ & & $\begin{array}{l}-0.0141344(-2.92) \\
{[0.003]^{* * *}}\end{array}$ \\
\hline $\ln C O 2 p c$ & $\begin{array}{l}-1.259725(-0.66) \\
{[0.507]}\end{array}$ & & \\
\hline $\ln T E N C p c$ & & & $\begin{array}{l}0.5989811(9.00) \\
{[0.000]^{* * *}}\end{array}$ \\
\hline$H D I$ & & $\begin{array}{l}1.537264(12.04) \\
{[0.000]^{* * *}}\end{array}$ & $\begin{array}{l}0.5217936(6.54) \\
{[0.000]^{* * *}}\end{array}$ \\
\hline$H D I^{2}$ & & & $\begin{array}{l}-0.0030183(-6.23) \\
{[0.000]^{* * *}}\end{array}$ \\
\hline$R \& D$ & & $\begin{array}{l}1.779873(3.19) \\
{[0.001]^{* * *}}\end{array}$ & \\
\hline$N U C E$ & & $\begin{array}{l}0.0109563(0.89) \\
{[0.374]}\end{array}$ & \\
\hline lnPFEoil & & $\begin{array}{l}0.1806539(0.87) \\
{[0.382]}\end{array}$ & \\
\hline EnDep & & $\begin{array}{l}0.0011651(0.12) \\
{[0.907]}\end{array}$ & \\
\hline$D_{2008}$ & $\begin{array}{l}0.6291273(4.37) \\
{[0.000]^{* * *}}\end{array}$ & $\begin{array}{l}-1.583588(-4.71) \\
{[0.000]^{* * *}}\end{array}$ & $\begin{array}{l}-0.0063557(-0.55) \\
{[0.584]}\end{array}$ \\
\hline $\mathrm{N}^{\circ}$ obs. & 336 & 336 & 336 \\
\hline $\mathrm{R}^{2}$ overall & 0.9738 & 0.9775 & 0.9820 \\
\hline RMSE & 0.6639567 & 1.68135 & 0.0465847 \\
\hline $\mathrm{Chi}^{2}$ & $12409.52[0.000]^{* * *}$ & $15499.56[0.000]^{* * *}$ & $19510.87[0.000]$ \\
\hline $\begin{array}{l}\text { Hausman test } \\
\text { p-value }\end{array}$ & $\begin{array}{l}\text { chi2 } 2(33)=69.350546 \\
{[0.00021763]}\end{array}$ & $\begin{array}{l}\text { chi2 }(34)=12.862732 \\
{[0.99961738]}\end{array}$ & $\begin{array}{l}\text { chi2(32) = 6.4697469 } \\
{[0.99999967]}\end{array}$ \\
\hline AR test & $\begin{array}{l}\mathrm{F}(1,27)=12.194 \\
{[0.0017]}\end{array}$ & $\begin{array}{l}\mathrm{F}(1,27)=39.479 \\
{[0.0000]}\end{array}$ & $\begin{array}{l}\mathrm{F}(1,27)=41.833 \\
{[0.0000]}\end{array}$ \\
\hline
\end{tabular}

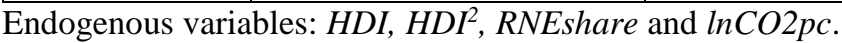

Exogenous variables: $\ln K p c$, $\ln$ Pop, $H K 1, H K 2, \ln L E$, EnDep, $R \& D, N U C E, \ln P F E o i l, \ln T E N C p c$, and all dummy variables used in the regressions.

Notes: numbers in parentheses are z-ratios and numbers in square brackets are p-values $\mathrm{P}>|\mathrm{z}| \mathrm{Chi}^{2}$ is the statistic for overall significance of coefficients. The coefficients of the specific-country dummy variables are not reported due to space limitations.

The null hypothesis in the Hausman test assumes that $2 s l s$ and $3 s l s$ are both consistent but $3 s l s$ is more efficient. The AR test uses the Wooldridge statistic for idiosyncratic error autocorrelation in panel data (see Wooldridge, 2002 and Drukker, 2003).

$* * *, * *, *$ indicate that coefficients are statistically significant at the $1 \%, 5 \%$ and $10 \%$ significance level, respectively. 
Concerning our core variable of interest, the renewable energy share, it has the expected positive effect on the development level, displaying a high statistical significance at the $1 \%$ level. It is predicted that, ceteris paribus, a one-percentage point increase in the use of this energy source will contribute to 0.31 point increase in the level of development. Renewable energy consumption associated with less carbon emissions contributes expressively to increase the sustainable levels of economic development. Finally, the $\mathrm{CO} 2$ emissions per capita associated mostly with the consumption of fossil energy sources affects negatively the human development levels as expected, but without having any statistical relevance. Therefore, we are not able to assess in a robust manner the harmful effects of carbon emissions on the development levels.

\subsection{The determinants of renewable energy consumption}

The second column of Table 3 shows the regression results by estimating equation (2) of the system. The dependent variable is the renewable energy consumption (RNEshare) explained by the country's development stage $(H D I)$, accessing therefore the feedback effects of the two variables. The other covariates are the $R \& D$ expenditure ratio (as percentage of $G D P$ ), the share of tertiary schooling (HK2), the nuclear energy consumption $(N U C E)^{5}$, the oil price (PFEoil), and the energy dependence from abroad (EnDep). A time-dummy is also used to control for the consequences of the financial crisis in 2008. The purpose for including these variables to explain the renewable energy consumption has been explained previously, defining the determinants of equation (2). All variables are in percentage form except the oil price and nuclear consumption that enter with the logarithmic transformation.

The obtained results are again satisfactory in terms of the degree of explanation as it is shown by the overall goodness of fit and joint statistical significance of coefficients. On the other hand, all coefficients confirm our expectations on the predicted effect of each explanatory variable in explaining total renewable energy consumption in the set of countries included in our sample. In particular, the impact of human development index is positive, confirming the hypothesis that countries with higher development level consume more energy coming from renewable sources friendlier to the environment. Therefore, and having into account the findings of equation (1) of our model, we establish a reciprocal relationship between the development stage of economies and the use of renewable energy. We have strong evidence from equation (1) that renewable energy consumption affects significantly the level of countries development, and from equation (2) that countries with higher level of development use more efficiently renewable energy. In particular, ceteris paribus, it is predicted that if human development index increases by one point (of the scale from 1 to 100), renewables consumption will increase by approximately 1.5 percentage points, and this impact is statistically significant at the $1 \%$ level. Therefore, renewable energy consumption quite sensitive to changes in the stage of economic development.

With what concerns the other fundamentals, the evidence is strong as expected on the importance of $R \& D$ spending (as percentage of $G D P$ ) favoring the development and consumption of renewable energy. Other things constant, it is estimated that one percentage point increase in the

\footnotetext{
${ }^{5}$ Because not all countries produce nuclear energy and in order not to reduce the panel data size, we have transformed this variable in the following way: first, we defined the ratio of nuclear energy to total energy consumption, then we subtracted this ratio from one, and finally we take the logarithm of this result. In this way, no observation is lost in the sample.
} 
$R \& D$ spending ratio is responsible for 1.78 percentage point increase in renewable energy consumption, and it is statistically significant at the highest level of $1 \%$. The production of alternative non-fossil sources of energy is highly dependent on the development of new technologies and research that should be financially supported by the responsible entities. In conjunction with the importance of the $R \& D$ activities, we observe that higher levels of human capital represented by the tertiary education, contribute positively to the usage and consumption of renewable energy, and this impact is statistically significant at the $1 \%$ level.

Another factor, which assumed to be important for encouraging the usage of renewable energy, was the price of oil consumption ${ }^{6}$. Our evidence shows a positive relationship between the two variables, but not statistically significant at the conventional probability levels. It was supposed that the price increase in oil consumption might be an incentive for using more intensively renewable sources of energy. The hypothesis that higher prices of fossil energy would encourage policy makers to develop strategies in favor of producing renewable energy sources is not confirmed by the data ${ }^{7}$.

With respect to the remaining variables, we are not able to establish a statistically robust relationship between the use of renewable energy and the nuclear energy consumption or the energy dependence from abroad. The coefficients of both variables are statistically insignificant at the conventional probability levels. Therefore, nuclear energy is not an impediment to the production of other renewable sources, and the energy dependence from abroad seems not to be a deterministic factor for developing renewable energy sources.

\subsection{The determinants of environmental pollution}

The third column of Table 3 reports the regression results of estimating equation (3) of the system. The dependent variable is the $\mathrm{CO} 2$ emissions per capita for each country and the first aim is to confirm the inverted U-shape relationship between carbon emissions and the stage of economic development. For this reason, $\mathrm{CO} 2$ emissions are related with $\mathrm{HDI}$ and its squared value. Other covariates to explain emissions are human capital skills through average years of schooling ( $H K 1)$, the total energy consumption per capita (TENCPc), and the renewable energy consumption (RNEshare). All variables are in logs, except the $H D I$ and its squared value, the renewable energy consumption, and the years of schooling. In general, the results are satisfactory if we consider the goodness of fit measure, the individual and joint significance of coefficients, and the expected impacts of the covariates. As seen the inverted U-shape hypothesis between $\mathrm{CO} 2$ emissions and $H D I$ is strongly supported by the regression analysis, since the coefficient of $H D I$ is positive and the coefficient of its squared value is negative, and both are statistically significant at the highest $1 \%$ level. This result confirms the hypothesis known as the Kuznets curve that at lower stages of economic development carbon emissions increase, but a level of development will be reached (the threshold point) where countries realize that measures should be taken to protect the environment against higher pollution. This threshold point can be found by taking the partial

\footnotetext{
${ }^{6}$ Regressions with gas or coal prices instead of oil prices indicated also statistical insignificance of the price factor.

7 During the period of analysis from 2004 to 2015, the price of fossil based energy (and oil-price oscillations) is lower than in the preceding periods, as a result of the continuous decline in demand worldwide for this kind of energy. In addition, oscillations in prices are not very substantial in this period.
} 
derivative of $\log C O 2 p c$ with respect to $H D I$ and its squared value $H D I^{2}$ and solve for $H D I$, which gives the value of $86.4^{8}$. Checking the data, we observe that the majority of countries in our sample have reached or overcome this stage of development over the whole period considered from 2004 to 2015, except Bulgaria, Croatia, Latvia, Lithuania, Hungary, Portugal, Romania, Slovakia, Poland, Malta and Cyprus. Slovenia reached this level in 2006, Spain and Czech Republic in 2010, Greece in 2012, and Estonia in 2013.

Considering the other covariates, we assert that human capital through the years of schooling has a negative impact on $\mathrm{CO} 2$ emissions as expected, revealing that each year increase in schooling average is responsible for $-8.3 \%$ reduction in emissions per capita, being statistically significant at the highest $1 \%$ level. Therefore, we confirm that pollution issues are highly associated with education levels contributing significantly toward a reduction in environmental pollution. Educated people better understand the benefits from using alternative clean sources of energies, environmentally friendly. On the other hand, more education skills will contribute in the development of cleaner energy technologies. In addition, our evidence shows that the higher the total energy consumption (dominated by fossil sources), the higher the $\mathrm{CO} 2$ emissions per capita and this positive impact is statistically significant at the $1 \%$ level. Namely, atmospheric pollution increases by approximately $0.60 \%$, on average, for every $1 \%$ increase in total energy consumption. In contrast, the use of renewable energy as a share of total energy consumption (RNEshare) contributes to reduce $\mathrm{CO} 2$ emissions. It is shown that every one-percentage point increase in the share of renewable energy sources is responsible for $-1.4 \%$ decrease in $\mathrm{CO} 2$ emissions per capita, which is a considerable effect.

Finally, the Hausman statistic, which is used to test the adequacy of the $3 s l s$ estimation approach over the $2 s l s$, shows that the $3 s l s$ for the renewable energy and the $C O 2 p c$ equations produce estimates that are more efficient. However, this hypothesis is not confirmed for the first equation of the system, since the null hypothesis is rejected. Furthermore, the serial correlation statistic testing the hypothesis of no autocorrelation of the idiosyncratic error terms (see Wooldridge, 2002) reveals that errors are $1^{\text {st }}$ order autocorrelated producing then inefficient estimators. These limitations of the static model can be overwhelmed by introducing dynamics into the estimated equations.

\section{Dynamic aspects of the system}

To introduce dynamics into the system we estimate equations (1) to (3) including the lagged dependent variable. In this way, we can distinguish the short-run and long-run effects and know the speed of adjustment of the dependent variable relatively to its desired or optimal level. Furthermore, estimating equations with lagged dependent variable is the way to solve the problem of the error autocorrelation. Estimating a dynamic model is also a part of the sensitivity analysis allowing controlling the robustness of the empirical findings established in the previous static analysis. The shortcoming of this estimation technique is that we lose one observation for each unit (country). The results obtained by $3 s l s$ with lagged dependent variable are reported in Table 4.

\footnotetext{
${ }^{8} \partial \log C O 2 / \partial H D I=0.5217936-2 * 0.0030183 H D I=0=>H D I=86.4$. We recall that $H D I$ is an index that takes values from 0 to 100 .
} 
Table 4. Dynamic estimation of the system with lagged dependent variable: 3 sls fixed effects panel data, 28 OECD countries, 2004-2015

\begin{tabular}{|c|c|c|c|}
\hline Variable & $\begin{array}{c}\text { Eq. (1) } \\
\text { Dependent variable } \\
H D I\end{array}$ & $\begin{array}{c}\text { Eq. (2) } \\
\text { Dependent variable } \\
\text { RNEshare }\end{array}$ & $\begin{array}{c}\text { Eq. (3) } \\
\text { Dependent variable } \\
\ln C O 2 p c\end{array}$ \\
\hline constant & $\begin{array}{l}53.53021(2.74) \\
{[0.006]^{* * *}}\end{array}$ & $\begin{array}{l}-28.99106(-3.61) \\
{[0.000]^{* * *}}\end{array}$ & $\begin{array}{l}-15.59042(-4.28) \\
{[0.000]^{* * *}}\end{array}$ \\
\hline $\ln K p c$ & $\begin{array}{l}0.8710845(4.89) \\
{[0.000]^{* * *}}\end{array}$ & & \\
\hline $\ln P o p$ & $\begin{array}{l}-2.411922(-1.55) \\
{[0.121]}\end{array}$ & & \\
\hline$H K 1$ & $\begin{array}{l}0.7938638(8.42) \\
{[0.000]^{* * *}}\end{array}$ & & $\begin{array}{l}-0.0439427(-3.66) \\
{[0.000]^{* * *}}\end{array}$ \\
\hline$H K 2$ & & $\begin{array}{l}0.0656572(2.30) \\
{[0.022]^{* *}}\end{array}$ & \\
\hline $\ln L E$ & $\begin{array}{l}0.2403678(4.07) \\
{[0.000]^{* * *}}\end{array}$ & & \\
\hline RNEshare & $\begin{array}{l}0.0553939(2.10) \\
{[0.035]^{* *}}\end{array}$ & & $\begin{array}{l}-0.000335(-0.15) \\
{[0.884]}\end{array}$ \\
\hline $\ln C O 2 p c$ & $\begin{array}{l}-0.6602699(-0.77) \\
{[0.441]}\end{array}$ & & \\
\hline $\operatorname{lnTENCpc}$ & & & $\begin{array}{l}0.4956903(9.91) \\
{[0.000]^{* * *}}\end{array}$ \\
\hline$R \& D$ & & $\begin{array}{l}0.5220649(1.71) \\
{[0.087]^{*}}\end{array}$ & \\
\hline$N U C E$ & & $\begin{array}{l}0.0019678(0.17) \\
{[0.866]}\end{array}$ & \\
\hline lnPFEoil & & $\begin{array}{l}0.2263796(1.20) \\
{[0.229]}\end{array}$ & \\
\hline EnDep & & $\begin{array}{l}0.0078358(0.91) \\
{[0.365]}\end{array}$ & \\
\hline$H D I$ & & $\begin{array}{l}0.2951407(3.09) \\
{[0.002]^{* * *}}\end{array}$ & $\begin{array}{l}0.4317311(4.82) \\
{[0.000]^{* * *}}\end{array}$ \\
\hline$H D I^{2}$ & & & $\begin{array}{l}-0.0026544(-4.88) \\
{[0.000]^{* * *}}\end{array}$ \\
\hline$D_{2008}$ & $\begin{array}{l}0.2292794(2.58) \\
{[0.010] * * *}\end{array}$ & $\begin{array}{l}-0.2884405(-1.49) \\
{[0.137]}\end{array}$ & $\begin{array}{l}0.0046812(0.52) \\
{[0.604]}\end{array}$ \\
\hline$H D I_{t-1}$ & $\begin{array}{l}0.369632(8.82) \\
{[0.000]^{* * *}}\end{array}$ & & \\
\hline RNEshare $_{t-1}$ & & $\begin{array}{l}0.796971(23.63) \\
{[0.000]^{* * *}}\end{array}$ & \\
\hline $\ln C O 2 p c_{t-1}$ & & & $\begin{array}{l}0.3056016(6.22) \\
{[0.000]^{* * *}}\end{array}$ \\
\hline Adjustment speed & 0.6303368 & 0.203029 & 0.6943984 \\
\hline $\mathrm{N}^{\circ}$ obs. & 308 & 308 & 308 \\
\hline $\mathrm{R}^{2}$ overall & 0.9892 & 0.9941 & 0.9850 \\
\hline RMSE & 0.4182314 & 0.8651322 & 0.042168 \\
\hline $\mathrm{Chi}^{2}$ & $28405.31[0.000]^{* * *}$ & $51820.67[0.000] * * *$ & $21702.71[0.000] * * *$ \\
\hline $\begin{array}{l}\text { Hausman test } \\
\text { p-value }\end{array}$ & $\begin{array}{l}\operatorname{chi} 2(33)=9.9297868 \\
{[0.99996571]}\end{array}$ & $\begin{array}{l}\operatorname{chi} 2(35)=3.9907372 \\
{[1]}\end{array}$ & $\begin{array}{l}\operatorname{chi} 2(33)=7.9136037 \\
{[0.99999794]}\end{array}$ \\
\hline
\end{tabular}

Endogenous variables: $H D I, H D I^{2}$, RNEshare and $\operatorname{lnCO2pc}$.

Exogenous variables: $\ln K p c$, $\ln L E, H K 1, H K 2$, $\ln P o p$, EnDep, $R \& D, N U C E$, $\ln P F E c o i l, \ln T E N C p c$ and all dummy variables used in the regressions.

Notes: numbers in parentheses are z-ratios and numbers in square brackets are p-values $\mathrm{P}>|\mathrm{z}| \mathrm{Chi}^{2}$ is the statistic for overall significance of coefficients. The coefficients of the specific-country dummy variables 
are not reported due to space limitations. The null hypothesis in the Hausman test assumes that $2 s l s$ and $3 s l s$ are both consistent but $3 s l s$ is more efficient.

$* * *, * *, *$ indicate that coefficients are statistically significant at the $1 \%, 5 \%$ and $10 \%$ significance level, respectively.

In general, the regression results are satisfactory in terms of the goodness of fit and statistical significance of coefficients. Most importantly, all coefficients of the lagged dependent variable are statistically significant at the highest $1 \%$ level, justifying therefore the dynamic specification of the model based on the partial adjustment principle.

With respect to the first equation, the coefficients are in general statistically significant and carry their expected signs, except for the CO2pc and population variables. As in Table 3, we are not able to confirm statistically the expected harming effects of environmental pollution on the development level. The novelty is that life expectancy is now statistically relevant at the $1 \%$, indicating that, in the short-run, a one percent increase in life expectancy is responsible for 0.0024 point increase in the development level ( 0.0038 is the long-run effect), ceteris paribus. All other effects of covariates are the expected ones and in conformity with the findings in Table 3. Considering the speed of adjustment, the evidence shows that $63 \%$ of the actual variation in HDI is adjusted to its desirable or optimal level within the same period, which is relatively a fast approach.

Regarding the second equation, the results confirm the findings of the static model in Table 3. It is shown that, as expected, high levels of education, $R \& D$ spending and the level of economic development positively affect the share of renewable energy consumption, and all are statistically significant at the conventional probability levels. In particular, in the short-run, every onepercentage point (p.p.) increase in tertiary education is responsible for 0.065 percentage point increase in the consumption of renewable energy sources, everything else constant. The long-run impact is even higher approximately 0.32 percentage point increase. The short-run impact of $R \& D$ is 0.52 p.p. and the long run 2.57 p.p. on the renewable energy consumption, but it is statistically significant at the $10 \%$ level only. Accordingly, the impact of the development level on the increase in renewable energy consumption is 0.30 p.p. in the short-run and 1.45 p.p. in the long-run, and statistically significant at the $1 \%$ level. Once more, as in the static model, we are not able to provide robust evidence that nuclear energy and the degree of external dependence of energy consumption are important determinants in explaining the consumption of renewable energy, since their coefficients are not statistically relevant. As in the static model, the price of oil loses its statistical importance as a short-run incentive to consume more renewable energy. Moreover, the speed of adjustment is rather slow, showing that only $20 \%$ of the actual variation of renewable energy share is adjusted to its desirable level within the same period.

The estimated third equation of the system also confirms the main conclusions drawn from the static model. That is, the negative and statistically significant impact of the level of education on the reduction in $C O 2 p c$ emissions confirming the hypothesis that education is important for understanding the necessity of respecting the atmospheric quality. It is shown that in the shortrun every year increase in the schooling attendance is responsible for approximately $4 \%$ decrease in $\mathrm{CO} 2 p c$ emissions (6.3\% is the long-run effect), everything else constant. Further, it is shown that the higher the consumption of total energy the higher the atmospheric pollution with a shortrun elasticity of $0.50 \%$ and a long-run impact of $0.71 .4 \%$. The positive impact of HDI and negative impact of its square value confirm the inverse U-shape relation between the level of 
development and $C O 2 p c$ emissions with a short-run threshold point in $H D I$ equal to 81.64 (scale from 0 to 100). An unexpected result is the statistical insignificance of the renewable energy share on $C O 2 p c$ emissions, despite having the expected negative impact. This is the main difference with the static model where this impact is statistically significant at the $1 \%$ level. Finally, the speed of adjustment shows that nearly $70 \%$ of the actual variation in $C O 2 p c$ emissions is adjusted toward the desired level revealing a rather quick adjustment process.

Overall, the Hausman test supports the hypothesis that the $3 s l s$ displays estimates, which are more efficient in comparison to the $2 s l s$ approach, and this is valid for the three equations of the system.

\section{Conclusions}

This study analyses the important connections between sustainable levels of economic development, renewable energy consumption and atmospheric pollution. The interrelations between these core variables is described by a system of equations, which is characterized by feedback effects and circular expanding tendencies. It is shown that a threshold level of development will be reached where countries will realize that measures should be taken in order to protect atmospheric degradation, which involves a process of developing new sources of nonfossil energy environmentally friendly. The deployment of renewable energy requires higher level of human capital skills and reallocation of resources to finance projects that develop new ways of cleaner energy. In turn, renewable energy contributes substantially for improving economic conditions and the level of sustainable development. This circular causation mechanism has not been considered in the literature before and this study aims to fill this gap.

This circular causation mechanism and interconnections between levels of development, renewable energy and atmospheric pollution is described in a system of three behavioral equations, which also identifies the determinants of these core variables. The equations of the system are simultaneously estimated by $3 s l s$, the most efficient method that controls for the endogeneity problem (feedback effects) and considers at the same time the important interconnections through the cross-equation error correlation. The model is applied to a set of 28 OECD countries using panel data over the recent period 2004-2015, where statistical information is available. Two versions of the model are estimated, the static one and the dynamic based on the partial adjustment principle.

The evidence of the static model shows that renewable energy is an important factor in explaining the stage of development in this set of countries, along with physical capital and standard skills of human capital as economic theory predicts. Population has its expected negative impact on economic development, since more income will be distributed among the increased number of inhabitants. Moreover, in contrast to what it was expected, health status through life expectancy and $\mathrm{CO} 2$ emissions do not exert a significant impact on the development level, despite the former displaying significance in the estimation of the dynamic model. Therefore, we are not able to show in a robust statistical manner the negative impact of atmospheric pollution on the economic development level.

With respect to the determinants of the renewable energy consumption, it is shown that higher human skills (through tertiary education), R\&D expenditures as percentage of GDP, and the development level, are important factors to enhance the use of energy sources friendlier to environment. With this evidence, it is established the clear interconnection between renewable 
energy and the stage of development with feedback tendencies, and the importance of human skills and innovation in developing new sources of energy. In contrast to what it was expected, nuclear energy is not an obstacle for developing renewable sources of energy, and the oil price and degree of energy external dependence do not exert any effect on the consumption of renewable energy.

Concerning the determinants of $\mathrm{CO} 2$ emissions, we first confirm the non-linear relationship between the pollution level and economic development expressed by the inverse U-shape quadratic form. It is shown that most of the 28 OECD countries considered in our sample achieved the threshold point of development (86.4 in a scale from 0 to 100), up to which measures are taken aiming to reduce atmospheric pollution. Standard human capital skills and the use of renewable energy consumption have their expected negative impact on $\mathrm{CO} 2$ emissions, confirming the idea that educated people better understand the importance of reducing atmospheric pollution and that the use of new sources of cleaner energy is the way to tackle this problem. As expected, total energy consumption contributes to the increase in $\mathrm{CO} 2$ emissions, since most of this energy is fossil in nature.

Finally, the dynamic specification of the model based on the partial adjustment mechanism, confirms in general the evidence found in the static model, having the advantage to determine the short-run and long-run effects and define the speed of adjustment. The adjustment speed is found to be higher in the development level and the atmospheric pollution and lower in the use of renewable energy. This is an expected result, since the deployment of renewable energy sources is a difficult task, requiring higher human capital skills and long-term innovation projects. 


\section{References}

Al-mulali, U., Fereidouni, H.G., Lee, J.Y., Sab, C.N.B.C. (2013). Examining the bidirectional long run relationship between renewable energy consumption and GDP growth. Renewable and Sustainable Energy Reviews, 22, 209-222.

Alper, A., Oguz, O. (2016). The role of renewable energy consumption in economic growth: Evidence from asymmetric causality. Renewable and Sustainable Energy Reviews, 60, 953959.

Apergis, N., Payne, J.E. (2010a). Renewable energy consumption and growth in Eurasia. Energy Economics, 32 (6), 1392-1397.

Apergis, N., Payne, J.E. (2010b). Renewable energy consumption and economic growth: Evidence from a panel of OECD countries. Energy Policy 38 (1), 656-660.

Apergis, N., Payne, J.E. (2011). The renewable energy consumption-growth nexus in Central America. Applied Energy, 88 (1), 343-347.

Apergis, N., Payne, J.E. (2012). Renewable and non-renewable energy consumption-growth nexus: Evidence from a panel error correction model. Energy Economics, 34 (3), 733-738.

Barro, R. (2001). Human capital: growth, history and policy - A session to honor Stanley Engerman. Human Capital and Growth. American Economic Review, 91(2), 12-17.

Bhattacharya, M., Paramati, S.R., Ozturk, I., Bhattacharya, S., 2016. The effect of renewable energy consumption on economic growth: evidence from top 38 countries. Applied Energy, $162,733-741$.

Bilgili, F. (2015). Business cycle co-movements between renewables consumption and industrial production: A continuous wavelet coherence approach. Renewable and Sustainable Energy Reviews, 52, 325-332

Bilgili, F., Ozturk, I. (2015). Biomass energy and economic growth nexus in G7 countries: Evidence from dynamic panel data. Renewable and Sustainable Energy Reviews, 49, 132-138.

Dogan, E. (2015). The relationship between economic growth and electricity consumption from renewable and non-renewable sources: a study of Turkey. Renewable and Sustainable Energy Reviews, 52, 534-546.

Drukker, D. M. (2003). Testing for serial correlation in linear panel-data models. The Stata Journal, 3, 168-177.

Ewing BT., Sari R., Soytas U. (2007). Disaggregate energy consumption and industrial output in the United States. Energy Policy (35), 1274-81.

Fang, Y. (2011). Economic welfare impacts from renewable energy consumption: The China experience. Renewable and Sustainable Energy Reviews, 15 (9), 5120-5128.

Hamit-Haggar, M. (2016). Clean energy-growth nexus in sub-Saharan Africa: Evidence from cross-sectionally dependent heterogeneous panel with structural breaks. Renewable and Sustainable Energy Reviews, 57, 1237-1244.

Inglesi-Lotz, R. (2016). The impact of renewable energy consumption to economic growth: A panel data application. Energy Economics, 53, 58-63.

Kahouli, B., \& Omri, A. (2017). Foreign direct investment, foreign trade and environment: New evidence from simultaneous-equation system of gravity models. Research in International Business and Finance, 42, 353-364.

Koçak, E., Şarkgüneşi, A. (2017). The renewable energy and economic growth nexus in Black Sea and Balkan countries. Energy Policy, 100, 51-57.

Kuznets, S. (1955). Economic growth and income inequality. American Economic Review, 45, $1-28$. 
López-Casasnovas, G., Rivera, B. and Currais, L. (2005). Health and Economic Growth: Findings and Policy Implications, MIT Press, Cambridge

Lucas, R. E. (1988). On the mechanics of economic development. Journal of Monetary Economics, 22 (1), 3-42.

Menegaki, A.N. (2011). Growth and renewable energy in Europe: A random effect model with evidence for neutrality hypothesis. Energy Economics, 33 (2), 257-263.

Menegaki, A.N. (2014). On energy consumption and GDP studies; A meta-analysis of the last two decades. Renewable and Sustainable Energy Reviews, 29, 31-36.

Ocal, O., Aslan, A. (2013). Renewable energy consumption-economic growth nexus in Turkey. Renewable and Sustainable Energy Reviews, 28, 494-499.

Ohler, A., Fetters, I. (2014). The causal relationship between renewable electricity generation and GDP growth: A study of energy sources. Energy Economics, 43, 125-139.

Omri, A. (2013). CO 2 emissions, energy consumption and economic growth nexus in MENA countries: evidence from simultaneous equations models. Energy economics, 40, 657-664.

Omri, A., \& Kahouli, B. (2014). Causal relationships between energy consumption, foreign direct investment and economic growth: Fresh evidence from dynamic simultaneous-equations models. Energy Policy, 67, 913-922.

Ozturk, I. (2010). A literature survey on energy-growth nexus. Energy Policy, 38 (1), 340-349.

Ozturk, I., Bilgili, F. (2015). Economic growth and biomass consumption nexus: Dynamic panel analysis for Sub-Sahara African countries. Applied Energy, 137 (1), 110-116.

Pao, H.T., Fu, H.C. (2013). Renewable energy, non-renewable energy and economic growth in Brazil. Renewable and Sustainable Energy Reviews, 25, 381-392.

Payne, J.E. (2009). On the dynamics of energy consumption and output in the US. Applied Energy, 86 (4), 575-577.

Payne, J.E. (2010). Survey of the international evidence on the causal relationship between energy consumption and growth. Journal of Economic Studies, 37 (1), 53-95.

Romer, P. M. (1986). Increasing returns and long-run growth. Journal of Political Economy, 94 (5), 1002-1037.

Sadorsky, P. (2009a). Renewable energy consumption and income in emerging economies. Energy Policy, 37 (10), 4021-4028.

Sadorsky, P. (2009b). Renewable energy consumption, $\mathrm{CO}_{2}$ emissions and oil prices in the $\mathrm{G} 7$ countries. Energy Economics, 31 (3), 456-462.

Sari R., Ewing BT., Soytas U. (2008). The relationship between disaggregate energy consumption and industrial production in the United States: An ARDL approach. Energy Economics 30 (5), 2302-2313.

Sebri, M. (2015). Use renewables to be cleaner: meta-analysis of the renewable energy consumption-economic growth nexus. Renewable and Sustainable Energy Reviews, 42, 657665.

Shahbaz, M., Rasool, G., Ahmed, K., Mahalik, M.K. (2016). Considering the effect of biomass energy consumption on economic growth: Fresh evidence from BRICS region. Renewable and Sustainable Energy Reviews, 60 (1), 1442-1450.

Tiba, S., \& Omri, A. (2017). Literature survey on the relationships between energy, environment and economic growth. Renewable and Sustainable Energy Reviews, 69, 1129-1146.

Tiba, S., Omri, A. (2017). Literature survey on the relationships between energy, environment and economic growth. Renewable and Sustainable Energy Reviews, 69, 1129-1146. 
Tiwari, A.K. (2011). A structural VAR analysis of renewable energy consumption, real GDP and $\mathrm{CO}_{2}$ emissions: Evidence from India. Economics Bulletin, 31 (2), 1793-1806.

Tugcu, C.T., Ozturk, I., Aslan, A. (2012). Renewable and non-renewable energy consumption and economic growth relationship revisited: evidence from G7 countries. Energy Economics, 34 (6), 1942-1950.

Wooldridge, J. M. (2002). Econometric Analysis of Cross Section and Panel Data. Cambridge, MA: MIT Press. 
CeBER Working Papers

(Available on-line at www.uc.pt/go/ceber)

2017-10 The interconnections between Renewable Energy, Economic Development and Environmental Pollution. A simultaneous equation system approach - Elias Soukiazis, Sara Proença \& Pedro André Cerqueira

2017-09 The Renminbi: A Warrior for Competitiveness? - Pedro Bação, António Portugal Duarte \& Matheus Santos

2017-08

Le Portugal et l'Euro - João Sousa Andrade

2017-07 The Effect of Public Debt on Growth in Multiple Regimes in the Presence of Long-Memory and Non-Stationary Debt Series - Irina Syssoyeva-Masson \& João Sousa Andrade

2017-06 The Blank and the Null: An examination of non-conventional voting choices - Rodrigo Martins

2017-05 Where is the information on USD/Bitcoins hourly price movements?- Helder Sebastião, António Portugal Duarte \& Gabriel Guerreiro

2017-04 The response of non-price competitiveness and productivity due to changes in passed income gaps. Evidence from the OECD countries - Pedro André Cerqueira, Micaela Antunes \& Elias Soukiazis

2017-03 Dutch Disease in Central and Eastern European Countries - João Sousa Andrade \& António Portugal Duarte

2017-02 On the gains of using high frequency data and higher moments in Portfolio Selection- Rui Pedro Brito, Hélder Sebastião \& Pedro Godinho

2017-01 Growth adjustments through non-price competitiveness and productivity. A cumulative causation approach-Elias Soukiazis, Micaela Antunes \& Pedro André Cerqueira

A série CeBER Working Papers foi iniciada em 2017. 